Article

\title{
Patient or Physician Centered Care?: Structural Implications for Clinical Interactions and the Overlooked Patient
}

\author{
Aaron B. Franzen \\ Sociology and Social Work Department, Hope college, VanZoeren 266, 41 Graves Place, \\ Holland, MI 49423-3698, USA; franzen@hope.edu
}

Received: 20 July 2017; Accepted: 16 August 2017; Published: 22 August 2017

\begin{abstract}
Patient-centered care is widely supported by physicians, but this wide-spread support potentially obscures the social patterning of clinical interactions. We know that patients often want religious/spiritual conversations in the context of medical care but the provision is infrequent. As there is regional variance in religiosity, a gap in the literature exists regarding whether patient populations' religiosity is connected to physicians' self-reported religious/spiritual interactions. Using a national sample of U.S. physicians linked to county-level measures, the author test whether both physicians' background and patient population characteristics are related to religious/spiritual interactions. Specifically, do physicians in more religious locations report more frequent religious interactions and is this dependent on whether the physician is also religious? Or does the religiosity of patient populations fail to explain variance in the frequency of inclusion? Logistic regressions with spatial lag terms highlight the importance of physicians' background for inclusion of religiosity/spirituality. County-level variance of religious concentration is largely unrelated to the inclusion of religiosity/spirituality. The provision of patient-centered care is complicated. The inclusion of something patient-specific, such as religious/spiritual content, may not depend on the characteristics of the patient population, but those of the physician they see.
\end{abstract}

Keywords: role perception; physicians; patient interactions; religion; patient-centered care

Going to see a doctor is rarely a welcomed experience. Physicians are needed because they are the professional charged with helping make sense of disparate and baffling physical indicators that something is amiss (Jutel 2011). This experience is less uncomfortable when the physician understands what we are feeling and treats us as an individual. For many, this includes religious beliefs and sentiments (Best et al. 2015).

There is often a gap between patients' desire for the inclusion of religion/spirituality and the provision of it within their medical care (Best et al. 2015). This research often accompanies or inspires increased calls for changes in medical education (Anandarajah and Mitchell 2007; Anandarajah et al. 2010; Koenig et al. 2010; Lucchetti et al. 2012; Puchalski and Larson 1998; Rasinski et al. 2011) and the creation of standardized history and physical instruments (for example Anandarajah and Hight 2001). Much of this change in medicine grows out of calls for better patient-centered care and assumes that physicians can or do attune with the identity and personhood of patients and respond in kind. In other words, this assumes that the inclusion of religion/spirituality flows out of the belief disposition of patient populations. If physician-patient population concordance is central, then inclusion would happen most often when religious physicians practice within religious counties. But inclusion could also be primarily driven by physicians' belief dispositions independent of patient population characteristics.

Recognition of the importance of religion for many people's identity can strengthen the ability of a physician to connect with patients, helping patients make sense of being ill (Curlin et al. 2005) and 
perceived relevance of religion depends at least in part on physicians' beliefs (Franzen 2016). But the dynamics of this relationship change with patient populations; namely, some regions of the country are more religious than others. There is a gap in the literature as we do not currently know how regional religiosity matters. The objective here is to determine the extent to which clinical interactions addressing religious concerns are related to the religious characteristics of the physician's county, the physician's own background, or both.

\section{Background}

\subsection{Culture, Patient-Centered Care, and Clinical Content}

Medical care has moved away from paternalistic medical interactions (Emanuel and Emanuel 1992) towards care more actively focused on patient inclusion and participation (Armstrong 2014). Early on, Engel sketched out his idea of effective medical care that included pertinent psychological and sociological issues (Engel 1977). While patient-centered care has been formulated in different ways, the values tied to the clinical actions have wide support (Kitson et al. 2013).

Though the form and implications of patent-centeredness may depend on clinical settings (Mead and Bower 2002), treating the patient as a person and not merely a medical problem does not appear to be in dispute (Kitson et al. 2013). Research on when and why patient-physician relationships break down has frequently focused on racial concordance with the implication that differing values or perspectives either help or hamper interactions. For example, black patients tend to have more frequent negative medical experiences with non-black physicians, especially those with implicit but not explicit racial biases (Penner et al. 2010). Minority patients also tend to have more negative views of medical care, with decreased adherence to recommendations if they sense a bias (Stepanikova and Cook 2009), even within non-verbal communication (Stepanikova et al. 2012). Stepanikova et al. show that this could be tied to lower levels of action-specific trust in the physician (Stepanikova et al. 2006). Patients seeing physicians of the same race tend to be happier with the care they receive (LaVeist and Nuru-Jeter 2002), even independent of "patient-centered communication" (Cooper et al. 2003; but see Lo and Bahar 2013).

The purpose of this quick review is to show that while much focus is on racial issues, non-concordance between physicians and patients can be problematic in clinical settings and for health outcomes. This is important here because many Americans are religious and many desire religious beliefs or related content to be a part of medical interactions (Best et al. 2015; Chatters 2000; Koenig 2014; Williams et al. 2011). Dubbin et al. argue that patients need the right kind of cultural health capital in order to connect with physicians (Dubbin et al. 2013). A physician may be interested in patient-centered care, but if the patient population does not have enough of the appropriate background to connect with the physician, a connection is unlikely to form. As such, conversations including religious content are most likely to happen when religious patient populations meet with a religious physician, as physicians with more salient religious beliefs also tend think religiosity/spirituality matters for patient health more often (Franzen 2016).

While this suggests an interaction effect, this need not be the case. For example, Lo and Bahar show that some minorities do not prefer physicians of the same ethnic background, with the caveat that physicians who acknowledge patients' personal identity matters more (Lo and Bahar 2013). In the present context, this could mean that physicians' willingness to discuss religion/spirituality with patients may matter more than whether they share the specific faith. Matching physician and patient cultural backgrounds is possibly less important than effective communication and empathy. This necessity of effective communication can be a particularly recalcitrant challenge in modern medical contexts where depersonalized medical systems have come to dominate patients' personal identities (Stevenson and Scambler 2005).

The implication is that a physician need not be religious to effectively interact with religious patient populations, but they do need to be attentive to individual patients within that religious 
population. The more religious a county's population, the more frequently religious conversations would occur within that county, assuming empathetic patient-centered care. Or, more formally:

H1: Religious discussions in clinical settings are more likely in more religious counties.

H2: Religious discussions in clinical settings will be most likely when religious physicians practice in more religious counties.

\subsection{Social Structure and Medical Interactions}

A third hypothesis is that social structural constraints matter more than cultural relationships in clinical interactions. That is, the physician has a role with rules guided by perceptions of appropriate behavior. Physicians face structural pressures to suppress personal and "less objective" dimensions of illness. Fostering personal connections with patients actually tends to decrease in physicians-to-be throughout professional socialization (Newton et al. 2008) as they learn to detach from patients and focus more on objective indicators (Fox 1997).

Behaviors flow from an accumulation and standardization of past experiences (Giddens 1984) that over time solidify certain cognitive schemas filling any context with interpretable meaning (Lizardo et al. 2016). This contextualized meaning informs the individual as to what role they ought to be playing at any given time. If a role is akin to a part that an actor plays on a stage (Goffman 1959), then social structure and institutions provide the script actors follow. This means that social structures impart implicit norms guiding actions associated with their realm of influence, and roles are any given person's perception of the relevant norms for action within a pertinent structure's social context. At its core, a person's identity may best be thought of as embodied and enacted social structures (Lizardo and Collett 2013).

It is not, however, the individual belief in a set of norms that standardizes the behaviors of individuals, but the collective support of those norms (Elder-Vass 2008, p. 289; Martin 2009; Schwalbe 1991). This means that the power of social institutions is tied not necessarily to individual beliefs in a given norm, but a tie to clusters of others also supportive of and generally enforcing the norm (Archer and Elder-Vass 2012, p. 102).

The medical profession has expectations for what it means to be a physician. As physicians go through their professional socialization process, they learn the actions that comprise the physician role. Medical students are primarily socialized into a biomedical model of illness whereby the strongest emphasis is placed on biological processes and indicators (Bishop 2008; Coulehan 2005; Pedersen 2010), and tend to care for patients accordingly (Cameron et al. 2015; Levinson et al. 2000). While the value of caring for persons and not only biological processes is fairly universal (Kitson et al. 2013), the actions implied by this value are not and this dimension of medical socialization and practice is frequently secondary (Pedersen 2010; Thornquist 1994), especially as it relates to religiosity/spirituality in medicine (Barnes et al. 2000; Culatto and Summerton 2015).

All people are, however, part of more than one network. A physician is part of a professional network and its associated norm expectations, but also networks outside this professional one. If identities are internalized roles associated with relational connections within social structures, then this also means that physicians carry more identities with them than necessary in medical contexts (Lizardo and Collett 2013). Non-medical networks often are unlikely to inform a physician's professional work because they are not pertinent to work within the clinic.

\subsection{Variance in Perceived Roles and the Place or Religion}

If structural constraints on behavior are conditioned by relational ties embedded within different domains of life and the importance of them, we should take this into account when trying to understand physicians' perception of their role. For shifts in role perceptions to occur, a physician needs to be tied into additional social institutions or structures that have competing or complementary groups of people with normative commitments. That is, their perception of a physician's role depends on their 
relational ties within different domains of life (not only the profession) and the resulting constellation of contextually activated roles and identities.

How much extra-medical structures or institutions influence the physician's perception of their role will depend upon at least two things: the strength of that network association, and the institution's claim on relevance. These influence the "depth" of the resulting cognitive schemes (Johnson-Hanks et al. 2011)—does it matter for all of one's life, or just a specific part? A physician may be deeply involved with the arts, for example, but this likely has very little impact on their actions as a physician. Being deeply religious, on the other hand, may influence their behavior as religion often makes far reaching claims on relevance, with a potentially more extensive and ubiquitous "sacred consciousness" (Ammerman 2014). The importance of religion to the physician, and the associated network ties, will influence the degree to which religion shifts their perception of other roles in life, such as being a physician. Religious congregations can foster this kind of bridging religious capital, fostering connections between religion and professions (Park et al. 2014). These religious networks have a stronger impact on perceptions for a deeply religious physician than another who attends a religious service once or twice a year (Franzen 2015).

For the purposes of this study this means that whether or not a physician discusses religiosity/spirituality with patients depends not necessarily on the religiosity of the patient population, but on the physician's perception of what it means to be a physician. Physicians are strongly influenced by the biomedical norms and expectations of the medical community, but may also be influenced by the norms and expectations of their religious community. The strength and form of the latter could slightly shift the perceived structural constraints imposed on the physician's clinical interactions, allowing them to include religiosity/spirituality where others may not.

H3: Physicians including religious content in clinical interactions will depend on their own religious/spiritual orientation and perceived relevance of religion for medicine.

\section{Data and Methods}

The data for this study are from the Religion and Spirituality in Medicine: Physicians' Perspectives (RSMPP) survey. The RSMPP is a national, non-clustered, self-administered survey of US physicians covering topics such as physician religious beliefs, interactions with patients and the place of religion in medical care (Curlin et al. 2006; Curlin et al. 2007). The sample was drawn from the American Medical Association Physician Masterfile in 2003. 1820 surveys were mailed out, with 1144 respondents and a response rate of 63\% (definition 4) (American Association for Public Opinion Research 2011).

These data were merged with two additional datasets for geographic information. Specifically, I included the percent within each physician's county who claim membership at a place of worship as found in the 2000 Religious Congregation and Membership Study (RCMS). With known sampling challenges, the adjusted percent is used here (see Finke and Scheitle 2005). Two measures from the 2000 US Census for county-level controls are included-the percent with more than a high school education and the county's Gini coefficient. The Gini coefficient reflects the county's inequality and varies from zero (perfect equality) to one (perfect inequality). These were included because a physician could avoid talking about anything personal with patients very different from their self (high rates of inequality and/or lower levels of education).

While data that matches patients with physicians would be preferable, this is not currently available. It is plausible that as the percent claiming to be religious increases in any given location so too will the likelihood that any given physician within that area will see a greater number of religious patients. This is especially true given the fact that very few patients actively select their physician (Victoor et al. 2012). As such, knowing population rates is not an unacceptable approximation for patient populations in lieu of alternative data. If the beliefs, values, and perspectives of a patient population matter, then we should see a relationship on a macro-level. 
Analytic Method and Variables Included

All included models are logistic regressions because the endogenous variables are categorical and violate the proportional odds assumption of cumulative logistic models. Initial models are without the mean-centered interaction term (H1), and subsequently added (H2). As the data no not allow for multi-level modeling, the approach used here includes the county-level variables in models with a geo-spatial lag variable (described below) to control for cross-county influences (patients crossing county lines to see a doctor).

The first two county-level measures help control for patient-physician dissimilarity. The first is the percent of the county's population with an education greater than high school. The second is the county's Gini coefficient (described above). For the religious composition of the physician's county, I have included the adjusted percent of the county retaining a congregational membership. As residents may cross county lines to attend religious services (hence a maximum over $100 \%$ in Table 1 ), the weighted mean of focal county's adjacent counties' religious concentration was calculated using GeoDa 1.4.0 (Anselin 1988). This spatial lag variable allows for the assessment and control for how much the endogenous variable is determined by the religious concentration of neighboring counties (Stroope et al. 2014 see Appendix B). A non-random geographic patterning of religious concentration is indeed present in the United States, indicated by the local Moran's I statistic (Anselin 2005) for contiguous autocorrelation and $G$ statistic (Ord and Getis 1995) for pockets of autocorrelation.

Table 1. Descriptive Statistics and Group Mean Differences.

\begin{tabular}{|c|c|c|c|c|c|c|c|c|c|}
\hline Variables & Range & Mean/\% & Std. Dev. & $\begin{array}{l}\text { SBNR vs. } \\
\text { RAS }\end{array}$ & $\begin{array}{c}\text { SBNR vs. } \\
\text { RBNS }\end{array}$ & $\begin{array}{c}\text { SBNR vs. } \\
\text { NROS }\end{array}$ & $\begin{array}{l}\text { RAS vs. } \\
\text { RBSN }\end{array}$ & $\begin{array}{l}\text { RAS vs. } \\
\text { NROS }\end{array}$ & $\begin{array}{c}\text { RBNS vs. } \\
\text { NROS }\end{array}$ \\
\hline Age & $28-66$ & 50.01 & 8.34 & -0.04 & -1.32 & -1.20 & -1.28 & -1.16 & 0.12 \\
\hline White & 0,1 & 79 & 0.41 & 0.06 & 0.04 & 0.04 & -0.03 & -0.03 & 0.00 \\
\hline Male & 0,1 & 74 & 0.44 & -0.07 & $-0.21 *$ & $-0.12 *$ & -0.13 & -0.05 & 0.09 \\
\hline Academic & 0,1 & 32 & 0.47 & -0.03 & -0.12 & -0.07 & -0.10 & -0.04 & 0.06 \\
\hline Faith Based Practice & 0,1 & 12 & 0.33 & -0.00 & 0.05 & 0.07 & 0.05 & $0.07 *$ & 0.02 \\
\hline Primary Care & 0,1 & 33 & 0.47 & 0.01 & -0.02 & 0.05 & -0.03 & 0.05 & 0.08 \\
\hline Religious Area & $0-110$ & 63.10 & 16.96 & -2.00 & $-7.08 *$ & -2.18 & -5.08 & -0.18 & 4.89 \\
\hline Religion Impacts Health & $1-5$ & 3.68 & 0.99 & $-0.47 *$ & 0.35 & $0.80 *$ & $0.82 *$ & $1.27^{*}$ & $0.45 *$ \\
\hline No Religion & 0,1 & 10 & 0.30 & $0.20 *$ & $0.21 *$ & -0.03 & 0.01 & $-0.23 *$ & -0.24 * \\
\hline Congregational Attendance & $1-9$ & 4.97 & 2.43 & $-3.13 *$ & $-2.29 *$ & $0.54 *$ & $0.83 *$ & $3.67 *$ & $2.83 *$ \\
\hline SBNR & 0,1 & 20 & 0.40 & - & - & - & - & - & - \\
\hline RBNS & 0,1 & 4 & 0.20 & - & - & - & - & - & - \\
\hline NROS & 0,1 & 22 & 0.41 & - & - & - & - & - & - \\
\hline RAS & 0,1 & 52 & 0.50 & - & - & - & - & - & - \\
\hline \multicolumn{10}{|l|}{ Dependent Variables } \\
\hline Share beliefs & 0,1 & 55 & 0.50 & $-0.26^{*}$ & -0.02 & $0.16^{*}$ & $0.23 *$ & $0.41 *$ & 0.18 \\
\hline Listen & 0,1 & 63 & 0.48 & -0.03 & 0.02 & $0.15^{*}$ & 0.05 & $0.18^{*}$ & 0.13 \\
\hline Change subject & 0,1 & 22 & 0.41 & 0.13 * & -0.07 & $-0.14 *$ & -0.20 * & $-0.27 *$ & -0.07 \\
\hline Encourage patient beliefs & 0,1 & 76 & 0.43 & -0.06 & 0.02 & $0.16^{*}$ & 0.08 & $0.22 *$ & 0.14 \\
\hline Pray with patient & 0,1 & 35 & 0.48 & $-0.18 *$ & -0.03 & 0.08 & 0.15 & 0.26 * & 0.11 \\
\hline
\end{tabular}

Note: The $\mathrm{n}$ for each variable ranges from 1006 to 1144 and all analysis were weighted and corrected for survey design. Tukey post hoc group mean comparisons; ${ }^{*}=p<0.05$.

The religious/spiritual typology used follows prior research (Franzen 2015; Jang and Franzen 2013; Marler and Hadaway 2002), and effectively encapsulates both personal and communal religious attachments (McClure 2017). Franzen (2015) showed that physicians' religious/spiritual orientations are possibly more helpful than other measures such as congregational attendance. RSMPP respondents were asked two questions-how religious and how spiritual they are. Each question had four response categories: very religious/spiritual, moderately religious/spiritual, slightly religious/spiritual or not religious/spiritual at all. The two affirmative and the two negative responses were collapsed, creating a two-by-two typology allowing for a system of dummies: "religious and spiritual," "spiritual but not religious," "religious but not spiritual," and "not religious or spiritual" (RAS, SBNR, RBNS and NROS). Religious orientations impact perceptions of religion-medicine relevance (Franzen 2016). The same measure is included here: "how much influence do you think religion/spirituality has on patients' health?" The response options ranged from 'very much' to 'very little to none'.

Other controls include how often the physician attends religious services and a dichotomous measure reflecting whether they claim a religious affiliation (Catholic, Protestant, Jewish, etc.) or 
not. Demographic controls include dummy measures for whether or not the physician is white, male, practice primary care, academic medicine, or are in a faith-based practice. Finally, we include their age.

The six dependent variables reflect a wide variety of possible patient interactions to assess whether the patient population is a factor in including religious/spiritual issues within clinical interactions. All of the following are dichotomous measures, with the first two being composed of two questions. The first reflects the physician's propensity to share his or her own beliefs and the second is their propensity to pray with patients. To assess sharing beliefs, respondent were asked "when, if ever, is it appropriate for a physician to talk about his or her own religious beliefs or experiences with a patient?" with responses being, "never," "only when the patient asks," and "whenever the physician senses it would be appropriate." The second question about sharing beliefs asked whether they "respectfully share my own religious ideas and experiences" when patients bring up religious/spiritual issues. Response options ranged from "never" to "always" with "not apply" marked as missing.

For whether or not the physician prays with patients, the first question asks, "when, if ever, is it appropriate for a physician to pray with a patient" with response options of "never," "only when the patient asks," and "whenever the physician senses it would be appropriate." The second question about praying asks how often they "pray with the patient" when they bring it up ("never" to "always"). As the two survey questions used within each dummy measure (share beliefs and pray) were not measured on the same scale, all four were first standardized and then the lower two quartiles assigned zero (physician does not do it) and the upper two quartiles assigned one (physician does do it). If the respondent fell into the negative category for either of the two measures, they were assigned to the negative category (0) reflecting that they do not share their beliefs or pray with patients, respectively.

The following endogenous variables have the same lead regarding how they respond when religious/spiritual topics come up with patients and responses ranging from "never" to "always" with "not apply" responses coded as missing. The dummy measures were split so that each category had roughly $50-75 \%$ of the respondents. The first is about listening to the patient-“I listen carefully and empathetically," with "always" (1) compared with all others. Next, respondents were asked whether they "try to change the subject in a tactful way", with at least "sometimes" (1) compared with all others. Finally, they were asked whether they "encourage patients in their own religious/spiritual beliefs and practices", with at least "often" do this (1) compared with all others.

The last two measures deal with how often patients bring up issues of religiosity/spirituality and how often physicians ask about these issues. First, respondents were asked, "in your experience, how often have your patients mentioned religious/spiritual issues like God, prayer, meditation, the Bible, etc.," with responses ranging from "never" to "always", with "not apply" coded as missing. Those reporting "often" or "always" mentioned these topics were coded as 1. Finally, respondents were asked whether they "ever inquire about patients' religious/spiritual issues". The response option was yes (1) or no (0), with "does not apply—I don't see patients" coded as missing.

\section{Results}

Table 1 shows descriptive statistics and group mean comparisons for religious/spiritual orientations. The physicians in the sample thought religion/spirituality influenced patients' health some $/$ much (mean $=3.68$ ), the average religious membership rate of physicians' counties is $63.1 \%$, and on average physicians attend religious services monthly. Religious and spiritual physicians make up the largest group in the sample, with $52 \%$ of the physicians. On average, about $55 \%$ share their beliefs with patients, $63 \%$ listen as patients share, $22 \%$ change the subject away from religiosity/spirituality, $76 \%$ encourage patients in their beliefs, and $35 \%$ pray with their patients. There are very few differences between the orientations and county religiosity mean scores apart from RBNS physicians being more likely to live in religious counties compared with SBNR physicians. Religious physicians (RAS and RBNS) attend religious services more than other physicians, with the highest mean score for RAS physicians. There are no mean differences in working at an academic institution or claiming primary care as a specialty. When looking at the dependent variables, we can see there are no mean differences 
between SBNR and NROS physicians and RBNS and NROS physicians, while there are notable differences between the other orientations and our dependent variables, especially when looking at RAS and NROS physicians.

Tables 2-4 show the logistic regression results. As the county-level results are highly consistent between models, I merely point out the notable insignificance of county-level characteristics. Higher levels of county education are linked to negligibly lower reported odds of sharing beliefs $(\mathrm{OR}=0.99)$ and listening to patients $(\mathrm{OR}=0.98)$. Physicians within more religious counties have marginally higher odds $(p<0.1, \mathrm{OR}=1.016)$ to change the subject away from religiosity/spirituality, but the interaction shows it is the physicians who do not think religiosity/spirituality matter within these religious counties that are negligibly more likely $(p<0.1, \mathrm{OR}=0.991)$ to change the subject (Table 3 , Models 1 and 2).

In support of H3, physicians' own religious orientation and religious practices are significant. In every model (Tables 2-4), thinking religiosity/spirituality matters for patient health is related to the inclusion of religion. SBNR physicians generally do not differ from RAS physicians, except that they share their own beliefs just over $40 \%$ less $(\mathrm{OR}=0.563)$. RAS physicians are not always significantly different from the other religious orientations, but when there are differences, they tend towards inclusion. It is, however, striking that there are no differences between religious/spiritual orientations in whether or not they pray with patients. Attendance is also linked to inclusion in thee of the six outcomes: with increased attendance there are increased odds of the physician sharing their own beliefs ( $\mathrm{OR}=1.122)$, praying with patients $(\mathrm{OR}=1.196)$, and asking them about their religious/spiritual beliefs $(\mathrm{OR}=1.134)$.

Localized structural connections may matter. Working in an academic setting is related to passive participation-decreased odds of sharing beliefs ( $\mathrm{OR}=0.723)$ but about $60 \%$ more likely to listening compared with non-academic ( $\mathrm{OR}=1.402)$. Further, those in faith based settings have decreased odds of changing the subject away from religion $(\mathrm{OR}=1.855)$. On the other hand, physicians working in a primary care setting have lower odds of changing the subject $(\mathrm{OR}=0.721, p=0.1)$ and they are about $50 \%$ more likely to ask patients about their religious/spiritual beliefs $(\mathrm{OR}=1.504)$. 
Table 2. Logistic regression of physicians sharing their beliefs and praying with patients.

\begin{tabular}{|c|c|c|c|c|c|c|c|c|c|c|c|c|}
\hline & \multicolumn{6}{|c|}{ Share Own Beliefs } & \multicolumn{6}{|c|}{ Pray with Patient } \\
\hline & \multicolumn{3}{|c|}{ M1 } & \multicolumn{3}{|c|}{ M2 } & \multicolumn{3}{|c|}{ M1 } & \multicolumn{3}{|c|}{ M2 } \\
\hline & OR & SE & $B$ & OR & SE & $B$ & OR & SE & $B$ & OR & SE & $B$ \\
\hline \multicolumn{13}{|l|}{ Physician Measures } \\
\hline White & 0.991 & 0.193 & -0.001 & 0.991 & 0.193 & -0.001 & 0.892 & 0.186 & -0.012 & 0.894 & 0.186 & -0.012 \\
\hline Male & 1.172 & 0.177 & 0.017 & 1.172 & 0.177 & 0.017 & 1.020 & 0.179 & 0.002 & 1.021 & 0.179 & 0.002 \\
\hline Academic Setting & $0.723+$ & 0.172 & -0.037 & $0.723+$ & 0.172 & -0.037 & 0.802 & 0.177 & -0.025 & 0.800 & 0.177 & -0.025 \\
\hline Faith based practice & 0.744 & 0.217 & -0.024 & 0.744 & 0.217 & -0.024 & 1.154 & 0.227 & 0.012 & 1.159 & 0.227 & 0.012 \\
\hline Primary care & 1.010 & 0.160 & 0.001 & 1.010 & 0.160 & 0.001 & 1.037 & 0.159 & 0.004 & 1.039 & 0.159 & 0.005 \\
\hline No Religion & 0.791 & 0.291 & -0.017 & 0.792 & 0.291 & -0.017 & 0.703 & 0.342 & -0.026 & 0.713 & 0.343 & -0.025 \\
\hline Congregational attendance & $1.122 * *$ & 0.045 & 0.070 & 1.122 ** & 0.045 & 0.070 & $1.196^{* * *}$ & 0.045 & 0.110 & $1.196^{* * *}$ & 0.045 & 0.109 \\
\hline RBNS $^{a}$ & 0.672 & 0.399 & -0.019 & 0.671 & 0.400 & -0.019 & 1.010 & 0.375 & 0.000 & 0.984 & 0.377 & -0.001 \\
\hline NROS a & $0.486^{* *}$ & 0.253 & -0.076 & $0.486^{* *}$ & 0.253 & -0.076 & 1.097 & 0.272 & 0.010 & 1.085 & 0.273 & 0.009 \\
\hline SBNR $^{\mathrm{a}}$ & $0.563 *$ & 0.233 & -0.057 & $0.563 *$ & 0.232 & -0.057 & 0.909 & 0.243 & -0.009 & 0.903 & 0.244 & -0.010 \\
\hline \multicolumn{13}{|l|}{ County Measures } \\
\hline Religious percent & 0.997 & 0.007 & -0.012 & 0.997 & 0.007 & -0.012 & 1.010 & 0.007 & 0.041 & 1.010 & 0.007 & 0.043 \\
\hline R/S influence* Relig. \% & - & - & - & 1.000 & 0.005 & -0.001 & - & - & - & 0.997 & 0.005 & -0.051 \\
\hline Religious Spatial Lag & 1.001 & 0.008 & 0.004 & 1.001 & 0.008 & 0.004 & 0.990 & 0.008 & -0.037 & 0.990 & 0.008 & -0.037 \\
\hline Gini & 19.559 & 3.095 & 0.022 & 19.559 & 3.095 & 0.022 & 5.975 & 2.969 & 0.013 & 6.091 & 2.972 & 0.013 \\
\hline Greater than HS & $0.987+$ & 0.008 & -0.034 & $0.987+$ & 0.008 & -0.034 & 0.986 & 0.009 & -0.034 & 0.987 & 0.009 & -0.034 \\
\hline$N$ & \multicolumn{6}{|c|}{1085} & \multicolumn{6}{|c|}{1085} \\
\hline
\end{tabular}

Source: Religion and Spirituality in Medicine: Physicians' Perspectives, 2000 US Census, 2000 Religious Congregation and Membership Study. $p<0.0011^{* * *} ; p<0.01 * * ; p<0.05^{*} ; p<0.1+$ (two-tailed test); a = RAS is comparison category. 
Table 3. Logistic regression of listening to patients and changing the subject.

\begin{tabular}{|c|c|c|c|c|c|c|c|c|c|c|c|c|}
\hline & \multicolumn{6}{|c|}{ Listen to Patient } & \multicolumn{6}{|c|}{ Change Subject } \\
\hline & \multicolumn{3}{|c|}{ M1 } & \multicolumn{3}{|c|}{ M2 } & \multicolumn{3}{|c|}{ M1 } & \multicolumn{3}{|c|}{ M2 } \\
\hline & OR & SE & $B$ & OR & SE & $B$ & OR & SE & $B$ & OR & SE & $B$ \\
\hline \multicolumn{13}{|l|}{ Physician Measures } \\
\hline White & 1.278 & 0.182 & 0.025 & 1.277 & 0.182 & 0.025 & $0.459 * * *$ & 0.212 & -0.079 & $0.459 * * *$ & 0.213 & -0.079 \\
\hline Male & 0.789 & 0.179 & -0.025 & 0.789 & 0.179 & -0.025 & $0.696+$ & 0.202 & -0.039 & $0.692+$ & 0.203 & -0.039 \\
\hline Academic Setting & $1.402 *$ & 0.170 & 0.038 & $1.403 *$ & 0.170 & 0.038 & 1.155 & 0.191 & 0.016 & 1.149 & 0.193 & 0.016 \\
\hline Faith based practice & 0.988 & 0.236 & -0.001 & 0.987 & 0.236 & -0.001 & $1.825^{*}$ & 0.277 & 0.049 & $1.855^{*}$ & 0.281 & 0.050 \\
\hline Primary care & 0.942 & 0.157 & -0.007 & 0.941 & 0.157 & -0.007 & $0.714+$ & 0.189 & -0.041 & $0.721+$ & 0.190 & -0.040 \\
\hline No Religion & 0.856 & 0.272 & -0.011 & 0.854 & 0.273 & -0.012 & 1.281 & 0.304 & 0.018 & 1.336 & 0.306 & 0.021 \\
\hline Congregational attendance & 0.982 & 0.043 & -0.011 & 0.981 & 0.043 & -0.011 & 0.919 & 0.052 & -0.051 & 0.918 & 0.052 & -0.052 \\
\hline RBNS $^{a}$ & 0.942 & 0.413 & -0.003 & 0.945 & 0.414 & -0.003 & $2.813^{*}$ & 0.412 & 0.049 & $2.658^{*}$ & 0.418 & 0.047 \\
\hline NROS ${ }^{a}$ & 0.594 * & 0.248 & -0.054 & $0.595 *$ & 0.248 & -0.054 & $1.666+$ & 0.282 & 0.053 & $1.616+$ & 0.283 & 0.049 \\
\hline SBNR $^{\mathrm{a}}$ & 0.976 & 0.229 & -0.002 & 0.978 & 0.228 & -0.002 & 1.568 & 0.276 & 0.045 & 1.523 & 0.277 & 0.042 \\
\hline \multicolumn{13}{|l|}{ County Measures } \\
\hline Religious percent & 0.995 & 0.007 & -0.020 & 0.995 & 0.007 & -0.020 & $1.016+$ & 0.008 & 0.064 & 1.013 & 0.009 & 0.053 \\
\hline R/S influence * Relig. \% & - & - & - & 1.000 & 0.005 & 0.007 & - & - & - & $0.991+$ & 0.006 & -0.141 \\
\hline Religious Spatial Lag & 1.000 & 0.007 & 0.002 & 1.000 & 0.007 & 0.002 & 0.997 & 0.009 & -0.009 & 0.997 & 0.010 & -0.011 \\
\hline Gini & 0.912 & 2.958 & -0.001 & 0.912 & 2.960 & -0.001 & 0.110 & 3.358 & -0.016 & 0.110 & 3.396 & -0.016 \\
\hline Greater than HS & $0.976^{* *}$ & 0.008 & -0.061 & $0.976^{* *}$ & 0.008 & -0.061 & 0.996 & 0.009 & -0.011 & 0.996 & 0.009 & -0.010 \\
\hline$N$ & \multicolumn{6}{|c|}{1041} & \multicolumn{6}{|c|}{1043} \\
\hline
\end{tabular}

Source: Religion and Spirituality in Medicine: Physicians' Perspectives, 2000 US Census, 2000 Religious Congregation and Membership Study. $p<0.001^{* * *} ; p<0.01^{* *} ; p<0.05^{*} ; p<0.1+$ (two-tailed test); a = RAS is comparison category. 
Table 4. Logistic regression of encouraging patient beliefs and asking about patients' religiosity/spirituality.

\begin{tabular}{|c|c|c|c|c|c|c|c|c|c|c|c|c|}
\hline & \multicolumn{6}{|c|}{ Encourage Patient Beliefs } & \multicolumn{6}{|c|}{ Ask about Patients' R/S } \\
\hline & \multicolumn{3}{|c|}{ M1 } & \multicolumn{3}{|c|}{ M2 } & \multicolumn{3}{|c|}{ M1 } & \multicolumn{3}{|c|}{ M2 } \\
\hline & OR & SE & $B$ & OR & SE & $B$ & OR & SE & $B$ & OR & SE & $B$ \\
\hline \multicolumn{13}{|l|}{ Physician Measures } \\
\hline White & 1.147 & 0.202 & 0.014 & 1.144 & 0.202 & 0.014 & $1.469 *$ & 0.190 & 0.039 & $1.469 *$ & 0.190 & 0.039 \\
\hline Male & 1.165 & 0.192 & 0.016 & 1.166 & 0.193 & 0.016 & $0.739+$ & 0.174 & -0.032 & $0.739+$ & 0.174 & -0.032 \\
\hline Academic Setting & 1.164 & 0.185 & 0.017 & 1.175 & 0.187 & 0.018 & 0.963 & 0.167 & -0.004 & 0.965 & 0.167 & -0.004 \\
\hline Faith based practice & 1.010 & 0.263 & 0.001 & 0.998 & 0.265 & 0.000 & 0.856 & 0.220 & -0.013 & 0.854 & 0.221 & -0.013 \\
\hline Primary care & 1.078 & 0.177 & 0.009 & 1.073 & 0.177 & 0.009 & $1.505^{* *}$ & 0.154 & 0.050 & $1.504^{* *}$ & 0.154 & 0.050 \\
\hline No Religion & $0.563 *$ & 0.285 & -0.042 & $0.544 *$ & 0.287 & -0.045 & 1.173 & 0.281 & 0.012 & 1.166 & 0.282 & 0.011 \\
\hline Congregational attendance & 0.979 & 0.050 & -0.013 & 0.979 & 0.049 & -0.013 & $1.134^{* *}$ & 0.044 & 0.077 & $1.134^{* *}$ & 0.044 & 0.077 \\
\hline RBNS $^{a}$ & 0.754 & 0.435 & -0.014 & 0.789 & 0.438 & -0.011 & $0.457+$ & 0.408 & -0.038 & $0.462+$ & 0.409 & -0.038 \\
\hline NROS ${ }^{a}$ & $0.421 * *$ & 0.268 & -0.089 & $0.428^{* *}$ & 0.268 & -0.087 & $0.604 *$ & 0.253 & -0.052 & $0.607 *$ & 0.254 & -0.052 \\
\hline \multirow{2}{*}{\multicolumn{13}{|c|}{ County Measures }} \\
\hline & & & & & & & & & & & & \\
\hline Religious percent & 0.995 & 0.007 & -0.022 & 0.996 & 0.007 & -0.018 & 0.994 & 0.007 & -0.026 & 0.994 & 0.007 & -0.026 \\
\hline R/S influence * Relig. \% & - & - & - & 1.006 & 0.005 & 0.094 & - & - & - & 1.001 & 0.005 & 0.022 \\
\hline Religious Spatial Lag & 0.995 & 0.008 & -0.019 & 0.995 & 0.008 & -0.018 & 1.002 & 0.007 & 0.005 & 1.002 & 0.007 & 0.005 \\
\hline Gini & 0.346 & 3.276 & -0.008 & 0.348 & 3.279 & -0.008 & 0.517 & 2.813 & -0.005 & 0.507 & 2.815 & -0.005 \\
\hline Greater than HS & 1.008 & 0.008 & 0.021 & 1.008 & 0.008 & 0.021 & 0.992 & 0.007 & -0.022 & 0.991 & 0.007 & -0.022 \\
\hline $\mathrm{N}$ & \multicolumn{6}{|c|}{1031} & \multicolumn{6}{|c|}{1048} \\
\hline
\end{tabular}

Source: Religion and Spirituality in Medicine: Physicians' Perspectives, 2000 US Census, 2000 Religious Congregation and Membership Study. $p<0.001^{* * *} ; p<0.01 * * ; p<0.05^{*} ; p<0.1+$ (two-tailed test); a = RAS is comparison category. 


\section{Discussion and Conclusions}

Three hypotheses were proposed for when or how religious/spiritual content is included within clinical interactions. The first two stating that patient conversations will depend at least in part on the composition of patient populations: counties with more religious populations will have more frequent religious/spiritual conversations, especially when physicians think religiosity/spirituality matter for health. Hypothesis three is compatible but not dependent on $\mathrm{H} 1$ and $\mathrm{H} 2$ in proposing that the physician's own beliefs explain variation in inclusion. Role perceptions shift and may even be formed in the context of the strength and relevance of non-medical ties, so even if patient population religiosity does not matter a physician's will. While $H 1$ and $H 2$ were not supported, $H 3$ was.

Much of the findings presented here expand on previous work showing that what physicians perceive to be relevant to their work as a physician will depend to some degree on their own beliefs (Franzen 2016). As such, if the physician does not personally have some cultural background that helps them connect the relevance of religion/spirituality to the professional work they do, personal beliefs of a patient population may not only be extraneous and unnecessary information, but completely overlooked.

While concordance is important for patient interactions, the present study emphasizes that this social relationship is complicated as perceptions of role performance derive from physicians' relational ties within different structural domains. In other words, while concordance may happen in some cases, this may not be the primary mode of interaction between physicians and patients. The primary mode of interaction between the two may actually be driven by past experiences within non-medical social structures influencing perceptions of behaviors within the clinic, and any given specific interaction (a sick visit, for example). A fairly complex matrix of structural relationships and constraints exists, influencing physician-patient interactions. The biomedical model of modern healthcare implies roles for both the patient and physician, and both largely follow those rules. The physician has taken on a professionally-defined role, but their perception of that role will shift according to external structural relationships perceived as relevant and dominant, as can be seen in the effect of congregational attendance (Park et al. 2014). What defines these extra-professional structural ties as strong enough and relevant, however, is something future work can and should define.

These findings echo related discussions about how social actors come to see their role and its associated actions as good or best as compared to other potential forms of that role; there is possibly more than one way to be a "good" doctor. It was argued here that the physician's perceptions of what is appropriate in the clinic have strong structural relationships that influence what they see as the role of a physician. Work within the sociology of morality shows social structures are linked to perceptions of what one should do in a given situation (Hitlin and Vaisey 2013; Rawls 1987; Rawls 2010; Schwalbe 1991), and a fruitful path for further work could focus on how the mix or even conflict of multiple structural ties impact physicians' perception of their work. Indeed, elsewhere Curlin has referred to physicians as "practical philosophers" because of the frequent link between personal moral views and the implication these have on professional work (Curlin 2008). Lawrence and Curlin (2007) even argue that religious and non-religious physicians have different ideas of what the "conscience" is and how one's conscience matters for both their own work and in thinking about other physician's actions. In this sense, there is always a moral dimension present in physicians' work, whether religious or not.

Power imbalances are almost always present when considering patient-physician interactions (Starr 1982). This, however, has implications for clinical interactions and what it means to be a "good" physician. Some argue that the ability to act morally depends on the ability to take other's perspectives into account (Morgan and Schwalbe 1990), which is necessarily shaped by past and present structural locations and relationships (Schwalbe 1991). This is important in terms of power for two reasons. First, power imbalances can lead to patients marginalizing their own expectations of physicians' care because "... a relative lack of [power] in a situation where values and interests are in conflict is likely to undermine an individual's sense of being able to put the results of any moral thought into 
action" (Schwalbe 1991, p. 295). This undermined sense of interactive efficacy with physicians can lead to a patient who acts how they think their physician wants them to act. As such, even though patients may desire religious/spiritual medical interactions (Best et al. 2015), they are likely to mute these expectations.

One may object, saying physicians often do value their patients as persons and practice patient-centered care. This brings me to the second reason why power imbalances are important in clinical settings. Discerning what the physician is communicating is necessary for patients because their health requires it, but the perspective-taking burden is much lower for the physician. Power imbalances undermine the physician's ability to take on patients' perspectives because their own interests do not require the amount of work necessary to do so (Schwalbe 1991, p. 295). As such, the physician may not have conflicting values, but the various pressures of clinical settings tend to perpetuate the habitual enaction of clinical formal rationality expressed via biomedical medicine that dominates medicine and professional socialization. This is why the discussion of how one's structural ties shift perceptions of what it means to be a physician is important. That shift and associated cognitive connections will lead to different clinical habits and perceptions of what a physician should do, helping explain why physicians reporting greater time pressures are still more likely to include religion in clinical interactions (Curlin et al. 2006). Power imbalances even decrease the physician's ability to notice the effect of the imbalances in her work (Schwalbe 1991), but as context forces a decreased adherence to habitual actions, as with increased medical severity, personal connections and perspective taking increases (Callero 1991). This may be why the inclusion of religion is consistently linked to severity-in those contexts, taking on the perspective of patients increases (Bernard et al. 1999; King and Bushwick 1994; Ramondetta et al. 2011; Williams et al. 2011).

One potential avenue for further research would be to see how these structural relationships influence role perceptions over time. Specifically, how would the formation or dissolution of different network associations influence a physician's perception of professional roles and patient interactions? Once a physician has made a connection between beliefs and their work as a physician it is possible that sustained interaction with the religious network is no longer necessary to support that connection.

The physician's connection to the social structure of medicine in their relationship with other physicians may also matter. Do they practice alone or are they in a large group with frequent contact with others? Do they work in a faith based practice or in an academic center? Do they only see other physicians while at work or do they also frequently attend conferences or interact "virtually" via an active research and publication agenda? Any or all of these additional structural forms could have different implications for the formation and change of the physician's perception of what it means to be a physician. In the present models, working in either an academic or faith-based setting influenced interactions, although not strongly or consistently.

A key limitation of this study is the inability to actually connect specific patients with their corresponding physician. The present data, however, are the best approximation for large scale, population-based effects. While this limitation is real and needs to be considered, aggregate county information may actually be the next best proxy as patients are largely passive health care consumers (Harris 2003) with very few actively choosing providers (Victoor et al. 2012). Another limitation is that the patient interactions included here are self-reported, and could be not only inaccurate due misremembering, but also patterned in accordance with the independent variable. That is, more religious physicians could report a greater number of religious/spiritual interactions than is true and non-religious physicians could report at a lower frequency than is true. With these limitations in mind, the present study is an important step towards understanding how perceptions of relevance within medical practice are shaped by both medical and extra-medical ties.

Acknowledgments: Thanks to Paul Froese for his support and comments throughout this project. Thanks also to Farr Culrin and the Program on Medicine and Religion at the University of Chicago for access to the data used here, although any mistakes are, as always, mine.

Conflicts of Interest: The author declares no conflict of interest. 


\section{References}

American Association for Public Opinion Research. 2011. Standard Definitions: Final Dispositions of Case Codes and Outcome Rate for Surveys. Lenexa: AAPOR.

Ammerman, Nancy Tatom. 2014. Sacred Stories, Spiritual Tribes: Finding Religion in Everyday Life. New York: Oxford University Press.

Anandarajah, Gowri, Frederic Craigie, Robert Hatch, Stephen Kliewer, Lucille Marchand, Dana King, Richard Hobbs, and Timothy P. Daaleman. 2010. Toward Competency-Based Curricula in Patient-Centered Spiritual Care: Recommended Competencies for Family Medicine Resident Education. Academic Medicine 85: 1897-904. [CrossRef] [PubMed]

Anandarajah, Gowri, and Ellen Hight. 2001. Spirituality and Medical Practice: Using the HOPE Questions as a Practical Tool for Spiritual Assessment. American Family Physician 63: 81-89. [PubMed]

Anandarajah, Gowri, and Maureen Mitchell. 2007. A Spirituality and Medicine Elective for Senior Medical Students: 4 Years' Experience, Evaluation, and Expansion to the Family Medicine Residency. Family Medicine 39: 313-15. [PubMed]

Anselin, Luc. 1988. Spatial Econometrics: Methods and Models. Dordrecht: Kluwer Academic Publishers.

Anselin, Luc. 2005. Exploring Spatial Data with GeoDa: A Workbook. Urbana: Center for Spatially Integrated Social Science.

Archer, Margaret S., and Dave Elder-Vass. 2012. Cultural System or Norm Circles? An Exchange. European Journal of Social Theory 15: 93-115. [CrossRef]

Armstrong, David. 2014. Actors, Patients and Agency: A Recent History. Sociology of Health E Illness 36: 163-74.

Barnes, Linda L., Gregory A. Plotnikoff, Kenneth Fox, and Sara Pendleton. 2000. Spirituality, Religion, and Pediatrics: Intersecting Worlds of Healing. Pediatrics 106: 899-908. [PubMed]

Bernard, Lo, Timothy Quill, and James Tulsky. 1999. Discussing Palliative Care with Patients. Annals of Internal Medicine 130: 744.

Best, Megan, Phyllis Butow, and Ian Olver. 2015. Do Patients Want Doctors to Talk about Spirituality? A Systematic Literature Review. Patient Education and Counseling 98: 1320-28. [CrossRef] [PubMed]

Bishop, Jeffrey P. 2008. Rejecting Medical Humanism: Medical Humanities and the Metaphysics of Medicine. Journal of Medical Humanities 29: 15-25. [CrossRef] [PubMed]

Callero, Peter L. 1991. Toward a Sociology of Cognition. In The Self-society Dynamic: Cognition, Emotion, and Action. Edited by Judith A. Howard and Peter L. Callero. New York: Cambridge University Press.

Cameron, Rachel A., Benjamin L. Mazer, Jane M. DeLuca, Supriya G. Mohile, and Ronald M. Epstein. 2015. In Search of Compassion: A New Taxonomy of Compassionate Physician Behaviours. Health Expectations 18: 1672-85. [CrossRef] [PubMed]

Chatters, Linda M. 2000. Religion and Health: Public Health Research and Practice. Annual Review of Public Health 21: 335-67. [CrossRef] [PubMed]

Cooper, Lisa A., Debra L. Roter, Rachel L. Johnson, Daniel E. Ford, Donald M. Steinwachs, and Neil R. Powe. 2003. Patient-Centered Communication, Ratings of Care, and Concordance of Patient and Physician Race. Annals of Internal Medicine 139: 907-15. [CrossRef] [PubMed]

Coulehan, Jack. 2005. Today's Professionalism: Engaging the Mind but Not the Heart. Academic Medicine 80: 892-98. [CrossRef] [PubMed]

Culatto, Avril, and Christopher B. Summerton. 2015. Spirituality and Health Education: A National Survey of Academic Leaders UK. Journal of Religion and Health 54: 2269-75. [CrossRef] [PubMed]

Curlin, Farr A. 2008. Commentary: A Case for Studying the Relationship between Religion and the Practice of Medicine. Academic Medicine 83: 1118-20. [CrossRef] [PubMed]

Curlin, Farr A., Marshall H. Chin, Sarah A. Sellergren, Chad J. Roach, and John D. Lantos. 2006. The Association of Physicians' Religious Characteristics with Their Attitudes and Self-Reported Behaviors Regarding Religion and Spirituality in the Clinical Encounter. Medical Care 44: 446-53. [CrossRef] [PubMed]

Curlin, Farr A., Ryan E. Lawrence, and John D. Lantos. 2007. Religion, Conscience, and Controversial Clinical Practices-Reply. New England Journal of Medicine 356: 1891-92. [CrossRef] [PubMed]

Curlin, Farr A., Chad J. Roach, R. Gorawara-Bhat, John D. Lantos, and Marshall H. Chin. 2005. How Are Religion and Spirituality Related to Health? A Study of Physicians' Perspectives. Southern Medical Journal 98: 761-66. [CrossRef] [PubMed] 
Dubbin, Leslie A., Jamie Suki Chang, and Janet K. Shim. 2013. Cultural Health Capital and the Interactional Dynamics of Patient-Centered Care. Social Science E Medicine 93: 113-20.

Elder-Vass, Dave. 2008. Integrating Institutional, Relational and Embodied Structure: An Emergentist Perspective. The British Journal of Sociology 59: 281-99. [CrossRef] [PubMed]

Emanuel, Ezekiel J., and Linda L. Emanuel. 1992. Four Models of the Physician-Patient Relationship. JAMA: The Journal of the American Medical Association 267: 2221-26. [CrossRef]

Engel, George L. 1977. The Need for a New Medical Model: A Challenge for Biomedicine. Science 196: 129-36. [CrossRef] [PubMed]

Finke, Roger, and Christopher P. Scheitle. 2005. Accounting for the Uncounted: Computing Correctives for the 2000 RCMS Data. Review of Religious Research 47: 5-22. [CrossRef]

Fox, Renée. 1997. Experiment Perilous: Physicians and Patients Facing the Unknown. New Brunswick: Transaction Publishers.

Franzen, Aaron B. 2015. Physicians in the USA: Attendance, Beliefs and Patient Interactions. Journal of Religion and Health 54: 1886-900. [CrossRef] [PubMed]

Franzen, Aaron B. 2016. Is This Relevant?: Physician Perceptions, Clinical Relevance and Religious Content within Clinical Interactions. Journal for the Scientific Study of Religion 55: 438-64. [CrossRef]

Giddens, Anthony. 1984. The Constitution of Society: Outline of the Theory of Structuration. Berkeley: University of California Press.

Goffman, Erving. 1959. The Presentation of Self in Everyday Life. Garden City: Doubleday.

Harris, Katherine M. 2003. How Do Patients Choose Physicians? Evidence from a National Survey of Enrollees in Employment-Related Health Plans. Health Services Research 38: 711-32. [CrossRef] [PubMed]

Hitlin, Steven, and Stephen Vaisey. 2013. The New Sociology of Morality. Annual Review of Sociology 39: 51-68. [CrossRef]

Jang, Sung Joon, and Aaron B. Franzen. 2013. Is Being 'Spiritual' Enough without Being Religious? A Study of Violent and Property Crimes among Emerging Adults. Criminology 51: 595-627. [CrossRef]

Johnson-Hanks, Jennifer, Christine A. Bachrach, S.Philip Morgan, and Hans-Peter Kohler. 2011. Understanding Family Change and Variation: Toward a Theory of Conjunctural Action. New York: Springer.

Jutel, Annemarie Goldstein. 2011. Putting a Name to It: Diagnosis in Contemporary Society. Baltimore: Johns Hopkins University Press.

King, Dana E., and Bruce Bushwick. 1994. Beliefs and Attitudes of Hospital Inpatients about Faith Healing and Prayer. The Journal of Family Practice 39: 349-52. [PubMed]

Kitson, Alison, Amy Marshall, Katherine Bassett, and Kathryn Zeitz. 2013. What Are the Core Elements of Patient-Centred Care? A Narrative Review and Synthesis of the Literature from Health Policy, Medicine and Nursing. Journal of Advanced Nursing 69: 4-15. [CrossRef] [PubMed]

Koenig, Harold G. 2014. The Spiritual Care Team: Enabling the Practice of Whole Person Medicine. Religions 5: 1161-74. [CrossRef]

Koenig, Harold G., Elizabeth G. Hooten, Erin Lindsay-Calkins, and Keith G. Meador. 2010. Spirituality in Medical School Curricula: Findings from a National Survey. International Journal of Psychiatry in Medicine 40: 391-98. [CrossRef] [PubMed]

LaVeist, Thomas A., and Amani Nuru-Jeter. 2002. Is Doctor-Patient Race Concordance Associated with Greater Satisfaction with Care? Journal of Health and Social Behavior 43: 296-306. [CrossRef] [PubMed]

Lawrence, Ryan E., and Farr A. Curlin. 2007. Clash of Definitions: Controversies about Conscience in Medicine. American Journal of Bioethics 7: 10-14. [CrossRef] [PubMed]

Levinson, Wendy, Rita Gorawara-Bhat, and Jennifer Lamb. 2000. A Study of Patient Clues and Physician Responses in Primary Care and Surgical Settings. JAMA 284: 1021-27. [CrossRef]

Lizardo, Omar, Robert Mowry, Braondon Sepulvado, Dustin S. Stoltz, Marhsall A. Taylor, Justin Van Ness, and Michael Wood. 2016. What Are Dual Process Models? Implications for Cultural Analysis in Sociology. Sociological Theory 34: 287-310. [CrossRef]

Lizardo, Omar, and Jessica L. Collett. 2013. Embarrassment and Social Organization: A Multiple Identities Model. Social Forces 92: 353-75. [CrossRef]

Lo, Ming-Cheng Miriam, and Roxana Bahar. 2013. Resisting the Colonization of the Lifeworld? Immigrant Patients' Experiences with Co-Ethnic Healthcare Workers. Social Science E Medicine 87: 68-76. 
Lucchetti, Giancarlo, Alessandra Lucchetti, and Christina M. Puchalski. 2012. Spirituality in Medical Education: Global Reality? Journal of Religion and Health 51: 3-19. [CrossRef] [PubMed]

Marler, Penny Long, and C. Kirk Hadaway. 2002. 'Being Religious' or 'Being Spiritual' in America: A Zero-Sum Proposition? Journal for the Scientific Study of Religion 41: 289-300. [CrossRef]

Martin, John Levi. 2009. Social Structures. Princeton: Princeton University Press.

McClure, Paul K. 2017. Something besides Monotheism: Sociotheological Boundary Work among the Spiritual, but Not Religious. Poetics 62: 53-65. [CrossRef]

Mead, Nicola, and Peter Bower. 2002. Patient-Centred Consultations and Outcomes in Primary Care: A Review of the Literature. Patient Education and Counseling 48: 51-61. [CrossRef]

Morgan, David L., and Michael L. Schwalbe. 1990. Mind and Self in Society: Linking Social Structure and Social Cognition. Social Psychology Quarterly 53: 148-64. [CrossRef]

Newton, Bruce W., Laurie Barber, James Clardy, Elton Cleveland, and Patricia O'Sullivan. 2008. Is There Hardening of the Heart during Medical School? Academic Medicine: Journal of the Association of American Medical Colleges 83: 244-49. [CrossRef] [PubMed]

Ord, J. Keith, and Arthur Getis. 1995. Local Spatial Autocorrelation Statistics: Distributional Issues and an Application. Geographical Analysis 27: 286-306. [CrossRef]

Park, Jerry Z., Jenna Griebel Rogers, Mitchell J. Neubert, and Kevin D. Dougherty. 2014. Workplace-Bridging Religious Capital: Connecting Congregations to Work Outcomes. Sociology of Religion 75: 309-31. [CrossRef]

Pedersen, Reidar. 2010. Empathy Development in Medical Education-A Critical Review. Medical Teacher 32: 593-600. [CrossRef] [PubMed]

Penner, Louis A., John F. Dovidio, Tessa V. West, Samuel L. Gaertner, Terrance L. Albrecht, Rhonda K. Dailey, and Tsveti Markova. 2010. Aversive Racism and Medical Interactions with Black Patients: A Field Study. Journal of Experimental Social Psychology 46: 436-40. [CrossRef] [PubMed]

Puchalski, Christina M., and David B. Larson. 1998. Developing Curricula in Spirituality and Medicine. Academic Medicine: Journal of the Association of American Medical Colleges 73: 970-74. [CrossRef]

Ramondetta, Lois, Alaina Brown, Gwyn Richardson, Diana Urbauer, Premal H. Thaker, Harold G. Koenig, Jacalyn B. Gano, and Charlotte Sun. 2011. Religious and Spiritual Beliefs of Gynecologic Oncologists May Influence Medical Decision Making. International Journal of Gynecological Cancer: Official Journal of the International Gynecological Cancer Society 21: 573-81. [CrossRef] [PubMed]

Rasinski, Kenneth A., Youssef G. Kalad, John D. Yoon, and Farr A. Curlin. 2011. An Assessment of US Physicians' Training in Religion, Spirituality, and Medicine. Medical Teacher 33: 944-45. [CrossRef] [PubMed]

Rawls, Anne Warfield. 1987. The Interaction Order Sui Generis: Goffman's Contribution to Social Theory. Sociological Theory 5: 136-49. [CrossRef]

Rawls, Anne Warfield. 2010. Social Order as Moral Order. In Handbook of the Sociology of Morality. Edited by Stephen Hitlin and Stephen Vaisey. New York: Springer, pp. 95-122.

Schwalbe, Michael L. 1991. Social Structure and the Moral Self. In The Self-society Dynamic: Cognition, Emotion, and Action. Edited by Judith A. Howard and Peter L. Callero. New York: Cambridge University Press.

Starr, Paul. 1982. The Social Transformation of American Medicine. New York: Basic Books.

Stepanikova, Irena, and Karen S. Cook. 2009. How Do American Black, White, Hispanic, and Asian Health Care Users Perceive Their Medical Non-Adherence? Research in the Sociology of Health Care 27: 47-66.

Stepanikova, Irena, Stefanie Mollborn, Karen S. Cook, David H. Thom, and Roderick M. Kramer. 2006. Patients' Race, Ethnicity, Language, and Trust in a Physician. Journal of Health and Social Behavior 47: 390-405. [CrossRef] [PubMed]

Stepanikova, Irena, Qian Zhang, Darryl Wieland, G.Paul Eleazer, and Thomas Stewart. 2012. Non-Verbal Communication between Primary Care Physicians and Older Patients: How Does Race Matter? Journal of General Internal Medicine 27: 576-81. [CrossRef] [PubMed]

Stevenson, Fiona, and Graham Scambler. 2005. The Relationship between Medicine and the Public: The Challenge of Concordance. Health (London) 9: 5-21. [CrossRef] [PubMed]

Stroope, Samuel, Aaron B. Franzen, Charles M. Tolbert, and F.Carson Mencken. 2014. College Graduates, Local Retailers, and Community Belonging in the United States. Sociological Spectrum 34: 143-62. [CrossRef]

Thornquist, Eline. 1994. Profession and Life-Separate Worlds. Social Science E Medicine 39: 701-13. 
Victoor, Aafke, Diana M. J. Delnoij, Roland D. Friele, and Jany J. D. J. M. Rademakers. 2012. Determinants of Patient Choice of Healthcare Providers: A Scoping Review. BMC Health Services Research 12: 272. [CrossRef] [PubMed]

Williams, Joshua A., David Meltzer, Vineet Arora, Grace Chung, and Farr A. Curlin. 2011. Attention to Inpatients' Religious and Spiritual Concerns: Predictors and Association with Patient Satisfaction. Journal of General Internal Medicine 26: 1265-71. [CrossRef] [PubMed] 